\title{
COLD CHAMBER DIE CASTING OF ALUMINIUM ALLOY: A CASE STUDY
}

\author{
Rupinder Singh ${ }^{1 *}$ \\ ${ }^{1}$ Production Engineering Department, GNDEC, Ludhiana, India 141006 \\ *Corresponding e-mail: rupindersingh78@yahoo.com
}

\begin{abstract}
In the present work cold chamber die casting solution of Al alloy has been investigated as a case study of industrial component (crankcase). The study presented in this paper is based upon Taguchi based model on dimensional accuracy in cold chamber die casting. The castings prepared at proposed parametric settings have been studied for functional validation of the parts, as per statistical control point of view. The result of study highlights significant improvement in dimensional accuracy (as regards to statistical process control is concerned) at proposed parametric settings of cold chamber die casting process.
\end{abstract}

Keywords: Cold chamber die casting, statistically controlled, dimensional accuracy, Aluminum alloy.

\section{INTRODUCTION}

Cold chamber die casting is used for casting alloys that require high pressure and have high melting temperature such as $\mathrm{Al}, \mathrm{Mg}, \mathrm{Cu}$ based alloys and other high melting point nonferrous alloys. Ahuett et al.1 highlighted that as regards to operational details in cold chamber die casting process is concerned, at first stage, with die closed and plunger withdrawn position, molten metal is poured into the chamber (see Figure 1a). After this plunger forces metal to flow into die, maintaining pressure during the cooling and solidification (see Figure 1b). Then plunger is withdrawn, die is opened, and part is ejected (see Figure 1c).

The literature reviews reveal that lot of work has been reported on process optimization of cold chamber die casting process (Singh \& Kapoor5, Mathews et al.6). But hitherto very less has been reported on effect of different process parameters on dimensional accuracy of cast component in cold chamber die casting as per statistical control point of view. Figure 2 shows cause and effect diagram of casting dimensional accuracy in cold chamber die casting process. The proper range of pressure has to be selected for efficient functioning of cold chamber pressure die casting process (Sabau \& Mishra7; Peng et al.8; Singh \& Kapoor9). Singh and Kapoor5 proposed a Taguchi based model for dimensional accuracy $(\Delta D)$ in cold chamber pressure die casting process (as a case study of crankcase). The present work is an extension of previously published macro model for $\Delta \mathrm{D}$ in cold chamber die casting process.

The main benefit of this approach is that one can understand and control the range of input parameters affecting the $\Delta \mathrm{D}$ of industrial components prepared by cold chamber die casting process for mass production (as regards to statistical process control is concerned). For present case study an industrial component, 'crankcase' has been selected as a benchmark (Ref. Figure 3).
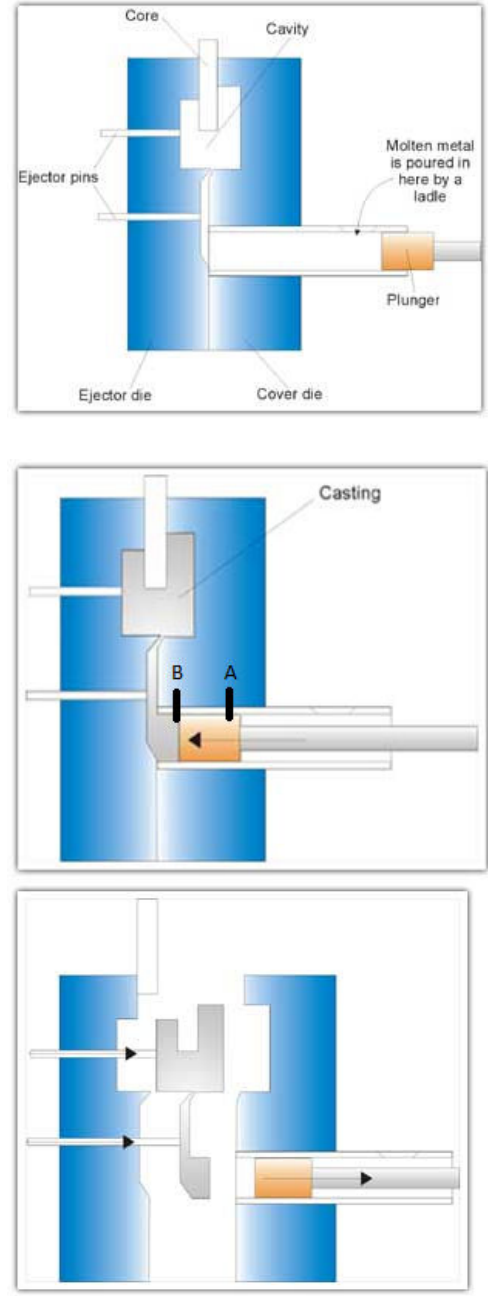

Figure 1. Steps in cold chamber die casting process, Kumar $^{2}$; Han \& Vishvanathan ${ }^{3}$, Domkin $^{4}$ 


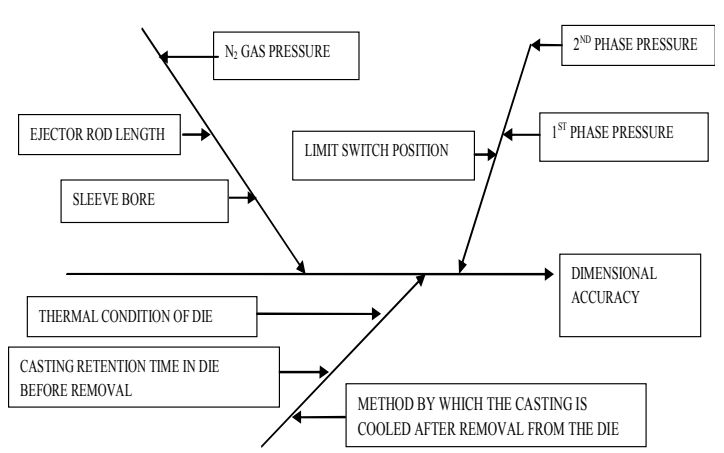

Figure 2. Cause and effect diagram of casting dimensional accuracy in cold chamber die casting.

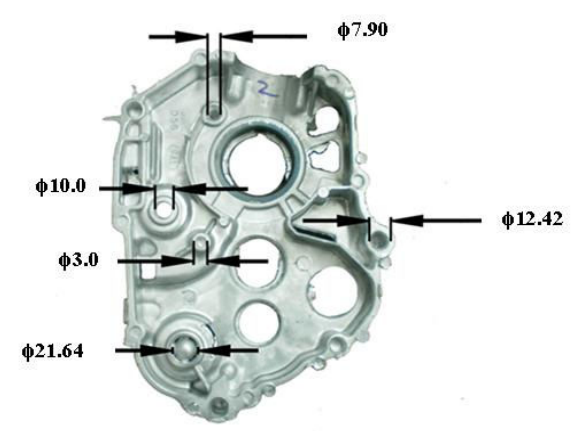

Figure 3. Bench mark for cold chamber die casting (all dimensions in $\mathrm{mm}$ ).

The fixed parameters for the present study are as under: - Aluminium Alloy: A380 (A1Si9Cu3)

- Temperature: $650^{\circ} \mathrm{C}$

- Equipment Detail:

a) Sleeve Bore: $70 \mathrm{~mm}$ (It is the size of the bore in sleeve from where the molten metal is poured).

b) Ejector Rod Length: $310 \mathrm{~mm}$ (Ejector rod is used to eject the casting from the die blocks).

c) Nitrogen (N2) Gas pressure: $85 \mathrm{~kg} / \mathrm{cm} 2$ (N2 gas is used to boost the injection pressure).

d) Thermal condition of die: $385-410^{\circ} \mathrm{C}$

e) Casting retention time in die before removal: $3-4 \mathrm{Sec}$ f) Air cooling of casting after removal from the die

The variable input parameters of the process and their levels are shown in Table1. It should be noted that 1 st phase pressure is the pressure by which the plunger moves the molten metal into the chamber reaches up to point A (as shown in Figure 1b). This pressure is important because, if pressure is increased then vortex flow will be made in the chamber and gases may trap in the molten metal and if the pressure decreases then the temperature of the molten metal is reduced. The 2 nd phase pressure is the pressure by which the plunger takes short and the molten metal flows into the die, plunger reaches at point $\mathrm{B}$ (as shown in Figure 1b). This pressure is important because, if pressure is reduced then the die may not be filled properly and if it increases then the molten metal may be split out from the die in the form of flash. The limit switch position guides the plunger where to finish the 1 st phase and from where to start the 2 nd phase.

Limit switch position is important because, if the distance is less, while plunger takes shot to flow metal into the die it will not fill properly and if this distance is more, then after shot there is a chance of the spill out of molten metal.

Table1. Variable inputs in cold chamber die casting process, Singh \& Kapoor $^{5}$

\begin{tabular}{|c|c|c|c|c|c|c|c|c|}
\hline \multicolumn{3}{|c|}{$\begin{array}{l}1^{\text {st }} \text { Phase } \\
\text { Pressure } \\
\left(\mathrm{N} / \mathrm{mm}^{2}\right)\end{array}$} & \multicolumn{3}{|c|}{$\begin{array}{l}2^{\text {nd }} \text { Phase Pressure } \\
\left(\mathrm{N} / \mathrm{mm}^{2}\right)\end{array}$} & \multicolumn{3}{|c|}{$\begin{array}{l}\text { Limit Switch } \\
\text { Position }(\mathrm{cm})\end{array}$} \\
\hline L1 & L2 & L3 & L1 & L2 & L3 & $\mathrm{L} 1$ & L2 & L3 \\
\hline 12 & 14 & 16 & 24.52 & 29.42 & 34.32 & 220 & 240 & 260 \\
\hline
\end{tabular}

There are four sections in this paper. Following this introduction section 2 describes experimentation for the cold chamber die casting process. Section 3 describes result and discussion section followed by conclusions.

\section{EXPERIMENTATION}

Table 2 and 3 respectively shows control $\log$ of experimentation and observations of final experimentation as per Taguchi L9 O.A.

Table 2. Control log of Experimentation.

\begin{tabular}{|c|c|c|c|}
\hline $\begin{array}{c}\text { Sr. } \\
\text { No. }\end{array}$ & $\begin{array}{c}\text { Variable 1 } \\
\left(\text { ( }^{\text {st }} \text { Phase }\right. \\
\text { Pressure }) \\
\mathrm{N} / \mathrm{mm}^{2}\end{array}$ & $\begin{array}{c}\text { Variable 2 } \\
\left(2^{\text {nd }} \text { Phase }\right. \\
\text { Pressure }) \\
\mathrm{N} / \mathrm{mm}^{2}\end{array}$ & $\begin{array}{c}\text { Variable 3 } \\
\text { (Limit Switch } \\
\text { Position) } \mathrm{cm}\end{array}$ \\
\hline 1 & 12 & 24.52 & 220 \\
\hline 2 & 12 & 29.42 & 240 \\
\hline 3 & 12 & 34.32 & 260 \\
\hline 4 & 14 & 24.52 & 240 \\
\hline 5 & 14 & 29.42 & 260 \\
\hline 6 & 14 & 34.32 & 220 \\
\hline 7 & 16 & 24.52 & 260 \\
\hline 8 & 16 & 29.42 & 220 \\
\hline 9 & 16 & 34.32 & 240 \\
\hline
\end{tabular}

The deviation $\Delta \mathrm{D}(\mathrm{mm})$ is the quantitative value by which the metal component shrinks or changes its dimensions after casting. The nominal dimensions on the drawing are recorded and compared with the dimensions of final castings on coordinate measuring machine $(\mathrm{CMM})$. The difference in both sizes gives the $\Delta \mathrm{D}$. Based upon Table $3, \mathrm{~S} / \mathrm{N}$ ratio of $\Delta \mathrm{D}$ for dimension $\phi 12.42 \mathrm{~mm}$ is given in Table 4 . 
Table 3. Observations of final experimentation for $\Delta \mathrm{D}$ for dimension $\phi 12.42 \mathrm{~mm}$

\begin{tabular}{|c|c|c|c|}
\hline \multirow{2}{*}{ Sr. No. } & \multicolumn{3}{|c|}{$\Delta \mathbf{D}(\mathbf{m m})$} \\
\cline { 2 - 4 } & ${ }^{*} \mathbf{R} 1$ & ${ }^{*} \mathbf{R 2}$ & ${ }^{*} \mathbf{R 3}$ \\
\hline 1 & 0.38 & 0.39 & 0.39 \\
\hline 2 & 0.35 & 0.35 & 0.34 \\
\hline 3 & 0.19 & 0.19 & 0.18 \\
\hline 4 & 0.11 & 0.14 & 0.13 \\
\hline 5 & 0.04 & 0.03 & 0.04 \\
\hline 6 & 0.15 & 0.14 & 0.15 \\
\hline 7 & 0.24 & 0.21 & 0.23 \\
\hline 8 & 0.3 & 0.31 & 0.3 \\
\hline 9 & 0.36 & 0.32 & 0.34 \\
\hline
\end{tabular}

*Note: * $R 1,{ }^{*} R 2$ and ${ }^{*} R 3$ are the runs of $\Delta D(\mathrm{~mm})$ obtained by three repetitions of experiments performed in order to reduce the experimental error

Table 4. $\mathrm{S} / \mathrm{N}$ ratio of $\Delta \mathrm{D}$ for dimension $\phi 12.42 \mathrm{~mm}$

\begin{tabular}{|c|c|c|c|c|c|}
\hline $\begin{array}{c}\text { Run } \\
\mathbf{1}\end{array}$ & $\begin{array}{c}\text { Run } \\
\mathbf{2}\end{array}$ & $\begin{array}{c}\text { Run } \\
\mathbf{3}\end{array}$ & \multicolumn{2}{c|}{$\begin{array}{c}\text { Sum } \\
\text { reciprocal }\end{array}$} & \multicolumn{2}{c|}{$\begin{array}{c}\text { S/N } \\
\text { ratio }\end{array}$} & $\begin{array}{c}\text { Ave } \\
\text { rage }\end{array}$ \\
\hline 0.38 & 0.39 & 0.39 & 0.1495333 & 8.252 & 0.3867 \\
\hline 0.35 & 0.35 & 0.34 & 0.1202 & 9.200 & 0.3467 \\
\hline 0.19 & 0.19 & 0.18 & 0.0348667 & 14.575 & 0.1867 \\
\hline 0.11 & 0.14 & 0.13 & 0.0162 & 17.904 & 0.1267 \\
\hline 0.04 & 0.03 & 0.04 & 0.0013667 & 28.643 & 0.0367 \\
\hline 0.15 & 0.14 & 0.15 & 0.0215333 & 16.668 & 0.1467 \\
\hline 0.24 & 0.21 & 0.23 & 0.0515333 & 12.879 & 0.2267 \\
\hline 0.3 & 0.31 & 0.3 & 0.0920333 & 10.360 & 0.3033 \\
\hline 0.36 & 0.32 & 0.34 & 0.1158667 & 9.360 & 0.3400 \\
\hline
\end{tabular}

Table 5 and 6 respectively shows the percentage contribution of various input parameters for $\Delta \mathrm{D}$ and improvement in $\Delta \mathrm{D}$ at proposed settings.

Table 5. Percentage contributions of input parameters for $\Delta \mathrm{D}$.

\begin{tabular}{|c|c|c|}
\hline & Sum square & $\mathbf{\% P}$ \\
\hline $1^{\text {st }}$ Phase Pressure & 212.26634 & 64.549466 \\
\hline $2^{\text {nd }}$ Phase Pressure & 16.030358 & 4.8747769 \\
\hline Limit Switch Position & 91.1271 & 27.711439 \\
\hline Error & 9.4191094 & 2.8643189 \\
\hline
\end{tabular}

Table 6. Improvement in results for $\Delta \mathrm{D}$

\begin{tabular}{|c|c|c|c|c|c|}
\hline & $\begin{array}{c}\text { Initial } \\
\text { reading }\end{array}$ & $\begin{array}{c}\text { Final } \\
\text { reading }\end{array}$ & $\begin{array}{r}\text { Perce } \\
\text { improv } \\
\Delta\end{array}$ & $\begin{array}{l}\text { ent } \\
\text { em } \\
\Delta \mathrm{D}\end{array}$ & $\begin{array}{l}\text { ge } \\
\text { nt in }\end{array}$ \\
\hline $\begin{array}{c}\Delta \mathrm{D} \\
(\mathrm{mm})\end{array}$ & 0.39 & 0.23 & \multirow{4}{*}{\multicolumn{2}{|c|}{ 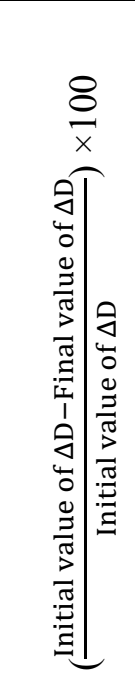 }} & \multirow{4}{*}{ 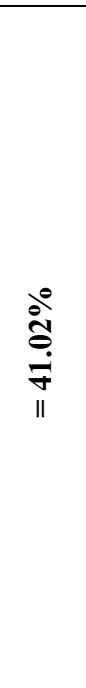 } \\
\hline 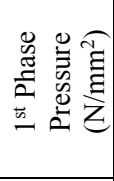 & 12 & 14 & & & \\
\hline 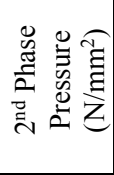 & 24.52 & 24.52 & & & \\
\hline 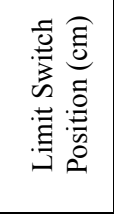 & 240 & 220 & & & \\
\hline
\end{tabular}

For $\Delta \mathrm{D}$ of casting, the best conditions are $1^{\text {st }}$ phase pressure $14 \mathrm{~N} / \mathrm{mm}^{2}, 2^{\text {nd }}$ phase pressure $24.52 \mathrm{~N} / \mathrm{mm}^{2}$ and limit switch position $220 \mathrm{~cm}$. These results are in-line with the observations made by other investigators $[2,5,9]$. For all other critical dimensions (Ref. Figure3) similar results were achieved. This may be explained on the basis of the fact that at proposed parametric settings of $1^{\text {st }}$ phase pressure of $14 \mathrm{~N} / \mathrm{mm}^{2}$ vortex flow of material in the chamber has been controlled and gas entrapment in the molten metal has been avoided. Further with $2^{\text {nd }}$ phase pressure of 24.52 $\mathrm{N} / \mathrm{mm}^{2}$ and limit switch position of $220 \mathrm{~cm}$ die was filled properly without any split of molten metal in the form of flash.

\section{RESULTS AND DISCUSSIONS}

The best parametric setting as suggested in Table 6 has been used for further statistical analysis. To study the statistical nature of process; six number of pieces were casted with Al alloy using cold chamber die casting at proposed settings. The measurement of all critical dimensions (Ref. Figure 2) has been made with CMM. Table 7 shows measurement of one of the critical dimension $(\phi 12.42 \mathrm{~mm})$ for analysis purpose. 
Table 7. Dimensional value obtained for cold chamber die casting of Al alloy

\begin{tabular}{|c|c|c|c|c|}
\hline S.No & Observation & Mean & $\begin{array}{c}\text { Above or } \\
\text { Below } \\
\text { Mean }\end{array}$ & $\begin{array}{c}\text { Up or } \\
\text { Down }\end{array}$ \\
\hline 1 & 12.4101 & 12.4154 & B & \\
\hline 2 & 12.4016 & 12.4154 & B & D \\
\hline 3 & 12.4151 & 12.4154 & B & U \\
\hline 4 & 12.4201 & 12.4154 & A & U \\
\hline 5 & 12.4203 & 12.4154 & A & U \\
\hline 6 & 12.4252 & 12.4154 & A & U \\
\hline Mean & 12.4154 & 12.4154 & Run=1 & $\begin{array}{c}\text { U \& } \\
\mathrm{D}=1\end{array}$ \\
\hline
\end{tabular}

*Note: $\mathrm{A}=$ Above the mean, $\mathrm{B}=\mathrm{Bel}$ ow the mean, $\mathrm{U}=\mathrm{Up}$ from previous reading and $\mathrm{D}=$ Down from previous reading.

The run chart was drawn for the values obtained (Ref. Figure 4).

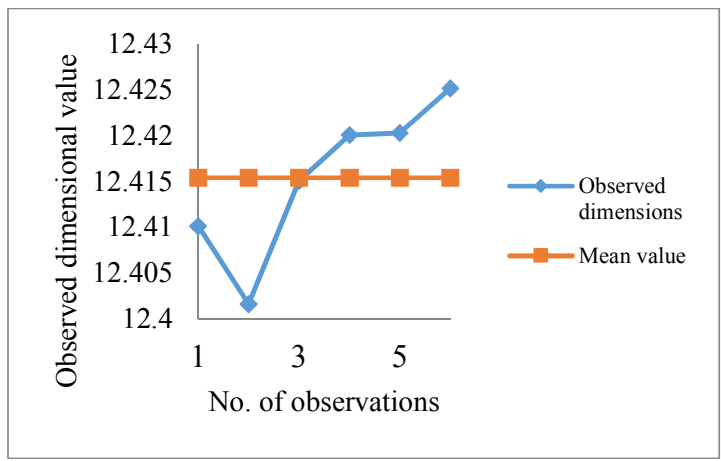

Figure 4. Run chart of the measured values of outer diameter

\section{Standard Normal Deviate $(\mathrm{Z})$}

If the mean and standard of population that is having normal distribution is $\mu$ and $\sigma$ respectively then for variable data $\mathrm{X}$ the standard normal deviate $\mathrm{Z}$ is defined as;

$\mathrm{Z}=\left(\mathrm{X}_{\mathrm{i}}-\mu\right) / \sigma$

Where $\mathrm{X}_{\mathrm{i}}$ is the variable data obtained, $\mu$ is the mean of data $\& \sigma$ is the standard deviation ${ }^{10-11}$.

\section{Calculation for $\mathbf{Z}$ (Standard Normal Deviate) Above \& Below}

$\mathrm{E}$ (run) $\mathrm{AB}=\mathrm{N} / 2+1$

Where $\mathrm{N}$ is the number of observations \& $\mathrm{E}$ (run)AB is the expected number of run Above \& Below

$\mathrm{E}$ (run) $\mathrm{AB}=6 / 2+1=4$ $\sigma \mathrm{AB}=\sqrt{ }(\mathrm{N}-1 / 4)$

Where $\sigma \mathrm{AB}$ is the standard deviation of Above \& Below

$\sigma \mathrm{AB}=\sqrt{ }(6-1 / 4)=1.118$

$\mathrm{ZAB}=(\mathrm{RUNAB}-\mathrm{E}($ run $) \mathrm{AB}) / \sigma \mathrm{AB}$

Where RUNAB is the actual number of run obtained above \& Below

$\mathrm{ZAB}=(1-4) / 1.118=-2.6834$

$|\mathrm{ZAB}|=2.6834$

\section{Calculation For Z (Standard Normal Deviate) Up} \& Down

$\mathrm{E}$ (run) $\mathrm{UP}=2 \mathrm{~N} \neg-1 / 3$

Where $\mathrm{N}$ is the number of observations \& $\mathrm{E}$ (run) UD is the expected number of run Up \& down

$\mathrm{E}($ run $) \mathrm{UP}=2 \times 6-1 / 3=3.667$

$\sigma \mathrm{UD}=\sqrt{ } 16 \mathrm{~N}-29 / 90$

Where $\sigma \mathrm{UD}$ is the standard deviation for Up \& Down

$\sigma \mathrm{UD}=\sqrt{ }(16 \times 6-29 / 90)$

$\sigma \mathrm{UD}=0.8628$

$\mathrm{ZUD}=(\mathrm{RUNUD}-\mathrm{E}($ run $) \mathrm{UD}) / \sigma \mathrm{UD}$

$\mathrm{ZUD}=(1-3.667) / 0.8628$

$\mathrm{ZUD}=-3.091$

$\mid$ ZUD $\mid=3.091$

\section{Calculation for $\mathbf{Z}$ Critical}

Critical value of $Z$ is obtained from Microsoft Excel formula, $=$ NORMSINV $(1-\alpha / 2)$.Normally decision making is done with certain margin of error $(\alpha) \&$ taken is equal to 0.005 i.e. there are $5 \%$ chances in arriving at wrong conclusion.

Zcrit $=1.959963$

\section{Decision Making}

If $\mid$ ZAB $\mid>$ Zcrit OR /\& $\mid$ ZUD $\mid>$ Zcrit, then non-random pattern exist In our case $|\mathrm{ZAB}| \& \mid$ ZUD $\mid$ are $>$ Zcrit, indicates existence of non random pattern. 


\section{For Normal Probability Curve}

Exercise of prediction of various statistical or drawing conclusions should not be undertaken unless the normality of distribution has been verified. The cumulative probability plot (Pi) can be written as

$\mathrm{Pi}=(\mathrm{S} . \mathrm{N}-0.5) / \mathrm{N}$

Where: S.N is serial number of observation of data arranged in ascending order and $\mathrm{N}$ is Total number of observations in the data set

\section{Standard Normal Deviate (Z)}

If the mean and standard of population that is having normal distribution is $\mu$ and $\sigma$ respectively then for variable data $\mathrm{X}$ the standard normal deviate $\mathrm{Z}$ is defined as;

$\mathrm{Z}=(\mathrm{Xi}-\mu) / \sigma$

The standard normal deviate follows normal distribution that has mean, $\mu=0$ and standard deviation, $\sigma=1$

$f(Z)=\square 1 / \sqrt{ }\left(2 \Pi \rrbracket \quad \square \mathrm{e}^{\wedge}\left(\mathrm{z}^{\wedge} 2 / 2\right)\right) \rrbracket$

The equation follows normal probability curve $\&$ any date close to it also follows normal probability curve.

$\mathrm{Z}$ is calculated by Microsoft Excel formula

$=\mathrm{NORMINV}(\mathrm{Pi})$

The values of Standard normal deviate were calculated using cumulative probability $\&$ dimensional values were arranged in ascending order as shown in Table 8 .

Table 8. Standard normal deviate \& outer diameter in ascending order.

\begin{tabular}{|c|c|c|c|}
\hline S.No & $\begin{array}{c}\text { Pi(Cumulative } \\
\text { Probability) }\end{array}$ & $\begin{array}{c}\text { Std. } \\
\text { Normal } \\
\text { Deviate Z }\end{array}$ & $\begin{array}{c}\text { Dimensional } \\
\text { Val. in mm }\end{array}$ \\
\hline 1 & 0.08333 & -1.38299 & 12.4016 \\
\hline 2 & 0.25 & -0.67449 & 12.4101 \\
\hline 3 & 0.416667 & -0.21043 & 12.4151 \\
\hline 4 & 0.58333 & 0.21043 & 12.4201 \\
\hline 5 & 0.75 & 0.67449 & 12.4203 \\
\hline 6 & 0.91667 & 1.382994 & 12.4252 \\
\hline
\end{tabular}

Based on Table 8 Normal probability curve was drawn to predict the probability as shown in Figure 5.

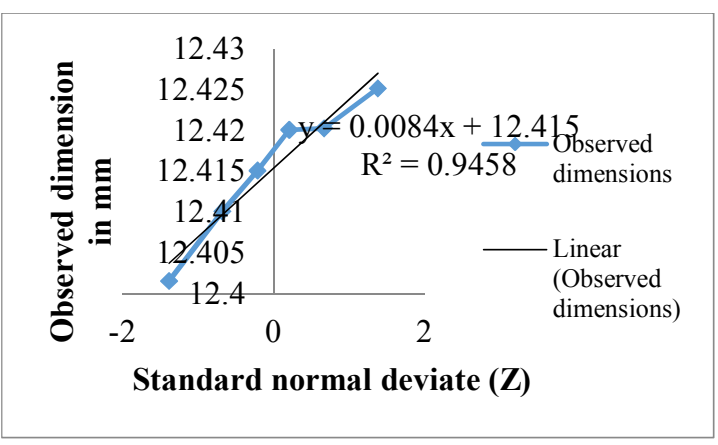

Figure 5. Normal Probability curve

From the above tests it is concluded that the aforesaid data follows non random pattern $\&$ is under normal probability curve. There are very strong chances that the process is under statistical control (at proposed parametric settings of pressure bifurcation) however X-bar chart \& R-bar chart cannot be drawn due to less number of observational data.

\section{CONCLUSIONS}

Following conclusions can be drawn from the present case study:

1.For cold chamber die casting process the best dimensional accuracy was obtained at $1 \mathrm{st}$ phase pressure $14 \mathrm{~N} / \mathrm{mm} 2$, 2nd phase pressure $24.52 \mathrm{~N} / \mathrm{mm} 2$ and limit switch position $220 \mathrm{~cm}$. Further for dimensional accuracy contribution of 1 st phase pressure, 2nd phase pressure and limit switch position is $64.55 \%, 4.87 \%$ and $27.71 \%$ respectively.

2.Strong possibilities are observed for the process under statistical control at these settings. Hence the process can be used for mass production in industrial applications. The adopted procedure is better for proof of concept and for the new product, for which the cost of production for dies and other tooling is more.

\section{REFERENCES}

1.Ahuett H, Garza R and Miller A, 2003, The effect of heat released during fill on the deflection of die casting, J. of Materials Processing Technology, Vol. 142, pp. 648- 658.

2.Kumar L., 2010, Multi-response optimization of process parameters in cold chamber pressure die casting: Thesis, Department of Mechanical Engineering, Thapar University, India.

3.Han Q and Vishvanathan S., 2003, Analysis of the mechanism of die soldering in aluminium die casting, Metallurgical and Material Transactions, Vol. 34A, pp. 139.

4.Domkin $\mathrm{H} \mathrm{T}, 2008$, Investigates soldering of cast alloys to the dies continuing source of die surface damage in the aluminium die casting, J. of Material Processing Technology, Vol. 209, pp. 4051-4061. 5.Singh R and Kapoor R, 2012, Effect of pressure on casting properties in cold chamber die casting, 
Lambert Academic Publishing AG \& Co. KG, Saarbrücken, Germany, ISBN 978-3-659-12721-2.

6. Matthew S, Dargusch A, Dourb G, Schauer C, Dinnis C M and Savaged G, 2006, The influence of pressure during solidification of high pressure die cast aluminium telecommunication components, J. of Materials Processing Technology, Vol. 180, pp. 3743.

7.Sabau A S and Vishvanathan S, 2002, Micro porosity prediction in aluminium alloy castings, Metallurgical and Materials Transactions, Vol. 33B, pp. 243.

8.Peng Z X, Cheng, $M$ and Allison, 2008, Determination of the heat transfer coefficient at metal-die interface of high pressure die casting process of AM50 alloy, Int. J. of Heat and Mass Transfer, Vol. 51, pp. 6032-6038.
9.Singh R and Kapoor R, 2013, Effect of pressure on casting properties in cold chamber die casting, J. of the Institution of Engineers (India): Series C, Vol. 94(2), pp. 147-153.

10.Singh $R$ and Singh G, 2014, Investigations for Statistically controlled investment casting solution of FDM based ABS replicas: Rapid Prototyping J., Vol 20(3), pp. 215-220.

11.Singh $\mathrm{K}$ and Singh R, 2013, Experimental investigations for statistically controlled vacuum moulding solutions of Al-SiC MMC, Applied Mechanics and Materials, Vol. 330, pp. 91-95. 